\title{
Environmental Peer Persuasion: How Moral Exporting and Belief Superiority Relate to Efforts to Influence Others
}

\author{
Alexander Maki \\ Vanderbilt University \\ Kaitlin T. Raimi \\ University of Michigan
}

Correspondence concerning this article may be addressed to Alexander Maki, Vanderbilt

Institute of Energy and Environment and Vanderbilt Climate Change Research Network, Vanderbilt University, 159 Buttrick Hall, PMB 407702, 2301 Vanderbilt Place,

Nashville, TN 37240. E-mail: alexander.maki@ vanderbilt.edu

(C) 2016. This manuscript version is made available under the Elsevier user license http://www.elsevier.com/open-access/userlicense/1.0/ 


\begin{abstract}
Traditional research on environmental behavior has explored the predictors of behavior change as a function of intervention efforts from an authority. The current research examines selfreported environmental behavior outside of these contexts, and in particular demonstrates the value in asking who attempts to influence the environmental behaviors of their peers. Environmental moral exporting and environmental belief superiority both related to efforts to influence the environmental behaviors of others, albeit in different ways. People high in moral exporting were more active in their efforts to influence the environmental behaviors of others, preferred a two-way dialogue between individuals, and enjoyed such interactions. Alternatively, individuals high in environmental belief superiority put relatively less effort into influencing others, compared to those high in environmental moral exporting, and tended to avoid environmental conversations. When individuals high in environmental belief superiority did have those conversations, they were likely to get frustrated and attempted to dominate the conversations. This research demonstrates the value in asking who tries to influence the environmental behavior of others and how they do so.
\end{abstract}

Keywords: moral exporting, belief superiority, environmental attitudes, environmental behavior, peer persuasion, interpersonal influence 


\section{Environmental Peer Persuasion: How Moral Exporting and Belief Superiority Relate to Efforts to Influence Others}

\section{Introduction}

\subsection{Background}

Every year near Thanksgiving, articles emerge online that coach people on how to convince their relatives over dinner of the realities of climate change. Of great relevance to such conversations, social and environmental psychologists have traditionally examined the factors that influence the likelihood of successful persuasion attempts. Much of this work has focused on experimental research contexts and researcher-induced persuasion efforts (e.g., Schultz, Nolan, Cialdini, Goldstein, \& Griskevicius, 2007). A multitude of persuasion methods used by authorities, including researchers, has been examined in the literature. These methods include framing environmental issues in terms of domains or analogies with which people are more familiar (Asensio \& Delmas, 2015; Corner \& Pidgeon, 2015; Stern \& Raimi, 2015), appealing to people's core moral and political values (Campbell \& Kay, 2014; Feinberg \& Willer, 2012), and making environmental issues personally relevant to people's physical environment (Hart \& Nisbet, 2012; McDonald, Chai, \& Newell, 2015).

However, most persuasion efforts that occur in the real world are not from the authorities, but rather from peer-to-peer. Despite how common conversations on environmental issues may be between family members, friends, and strangers, we know shockingly little about how people approach these conversations. Furthermore, even though certain types of people are probably more likely to initiate and persist in these interpersonal conversations, we know even less about theoretically-grounded individual differences that may relate to who tries to influence the environmental behaviors of others through conversations (Swim, 2013). 


\subsection{Efforts to Influence the Environmental Beliefs and Behaviors of Others}

Early work in environmental psychology focused on the spread, or diffusion, of environmental behaviors between individuals. For example, researchers considered the factors that make it more likely that energy-efficient technologies spread through one's social network over time (Brown, 1984; Darley, 1978). More recently, particular attention has been paid to adoption of home solar panels across shared geographical space (Noonan, Hsieh, \& Matisoff, 2013; Zhang, Vorobeychik, Letchford, \& Lakkaraju, 2016). Much of this research has focused on whether environmental behaviors spread over time, rather than on the processes that lead to this spreading of environmental behaviors. However, recent work has begun to examine how these behaviors may spread. Southwell and Murphy (2014), for example, found that those who purchase home weatherization improvements are more likely to talk to their friends and family members about the topic of home weatherization compared to those who do not purchase home weatherization improvements. People tended to engage in these conversations out of a desire help other people save money, but also to encourage others to engage in positive environmental actions. Other findings suggest that people often avoid discussing environmental topics like climate change in part due to inaccurate perceptions of others' beliefs (Geiger \& Swim, 2016).

Potential processes explaining the spread of environmental behaviors include modeling of behavior (Bandura, Ross, \& Ross, 1963), displays of social norms (Schultz et al., 2007), direct confrontations with others engaged in a harmful environmental behavior (Nolan, 2013), active persuasion attempts (Burn, 1991; Peterson, Smith, Tannenbaum, \& Shaw, 2009), and passive introductions of the topic in conversation without overt attempts to persuade (Rodgers \& Rowe, 1993; Southwell \& Murphy, 2014). All of these processes could help explain how one person influences another's environmental behavior. Yet little work in the environmental psychology 
area has considered individual differences that make it more likely that people will attempt to influence the environmental beliefs and behaviors of others through these processes. One exception is work by Nolan (2013), who found that individuals vary in both their willingness to confront litterers and their perceptions of how effective it is to intervene to stop littering. However, greater appreciation of the types of individuals who try to influence the environmental beliefs and behaviors of others more generally would help us appreciate when behaviors tend to spread during interpersonal interactions.

Two individual differences are of particular relevance when considering this question of who approaches others about environmental issues: environmental moral exporting and environmental belief superiority.

\subsection{Environmental Moral Exporting and Interpersonal Influence}

Moral exporting is one way in which people try to influence the behaviors of others. Moral exporting has traditionally been explored in political contexts, and refers to people's willingness to try to get others to adopt their moral values (Peterson et al., 2009). People high in moral exporting tend to have both a strong belief about moral issues and an action orientation toward influencing others. Political conservatives, those high in need for closure, and those professing moral absolutism tend to be higher in moral exporting, potentially reflecting their desire for a social environmental that is consistent with their own values (Peterson et al., 2009).

Although general moral exporting tendencies appear to be more likely in conservatives, this may not be the case for domain-specific moral exporting. Moral exporting was originally conceptualized as a general orientation, yet people may vary in how much they try to export their moral values in distinct domains, including their environmental values. Those who endorse environmental moral exporting beliefs should be more willing to try to change others' minds 
about environmental issues, and they should be more likely to try to influence the environmental behaviors of other people. Even though conservatives are more likely to engage in general moral exporting, Gallup polling suggests that liberals tend to rank environment-related issues, including climate change, as more important than conservatives do (Jones, 2015). Thus, liberals may actually be more likely to engage in environmental moral exporting due to the strength of their beliefs in this domain. Such a finding specific to environmental moral exporting would add important nuance to the current general moral exporting literature.

Though individuals high in moral exporting should be more likely to hold strong views about environmental issues, environmental moral exporting does not presume a direction of belief. For many people with strong environmentally relevant beliefs, those beliefs are proenvironmental. Yet they do not have to be pro-environmental to be strongly held or subject to moral exporting. Imagine, for example, a conservative who is a committed climate change skeptic and sees the "hoax" of climate change as the most important issue of our time. She might spend a great deal of effort trying to convert others to her position. Thus, whereas liberals as a group may be higher in environmental moral exporting than conservatives, this characteristic of the construct allows us to consider conservatives who are also high in environmental moral exporting.

This characteristic makes environmental moral exporting conceptually distinct from similar constructs in the literature, such as environmental identity (Whitmarsh \& O’Neill, 2010), environmental attitudes (Milfont \& Duckitt, 2010), and environmental values (Schultz \& Zelezny, 1999) that presume a particular direction of beliefs or attitudes. Furthermore, holding certain environmental attitudes or identifying as an environmentalist does not necessarily mean people are willing to act on their attitudes or identity in interpersonal contexts. Thus, 
environmental moral exporting may be a particularly useful individual difference to consider when trying to understand interpersonal environmental influence and environmental conversations.

In addition to exploring how environmental moral exporting relates to efforts to influence others, people high in moral exporting may have distinct types of conversational experiences when engaging with others. They may be eager to talk to others about environmental issues, may enjoy the conversations, and - given their action orientation—may desire a sincere interaction that can lead to meaningful change. People high in environmental moral exporting should be interested in creating a social environment that matches their values, thus making them more likely to be willing to engage in other social vigilantism efforts, more willing to confront the transgressions of others, and more optimistic about the effectiveness of their efforts. Exploring how environmental moral exporting relates to these constructs would help tease apart the unique ways in which environmental moral exporting relates to efforts to influence others' environmental behaviors and individuals' conversational experiences.

\subsection{Environmental Belief Superiority and Interpersonal Influence}

Related to environmental moral exporting is the concept of environmental belief superiority. Belief superiority is the belief that one's own views are more correct than other positions (Raimi, Jongman-Sereno, \& Leary, under review). Belief superiority has also been studied as a general construct (general belief superiority; GBS), one that is related to a number of others constructs including social vigilantism, overconfidence about skills and traits, dogmatism, and the certainty and confidence with which people hold their beliefs (Raimi et al., under review). 
In addition to these linear relationships between general belief superiority and related constructs, a pattern has emerged with belief superiority, in which the more extreme people's attitudes are on a given subject, the more superior they tend to feel about those beliefs (Brandt, Evans, \& Crawford, 2015; Raimi et al., under review; Toner, Leary, Asher, \& Jongman-Sereno, 2013). This pattern is found regardless of the direction of the attitude. For example, people who hold extremely liberal political beliefs are just as likely as those who hold extremely conservative beliefs to think that those views are superior (Brandt et al., 2015; Toner et al., 2013). This suggests another possible relationship between attitude direction and environmental moral exporting. Because people on the extremes of either side of an issue are more likely to report belief superiority, people who hold more extreme political views may also tend to be higher in moral exporting on both sides of the spectrum. Similarly, just as people could have both general and domain-specific moral exporting preferences, people report general feelings of belief superiority and belief superiority in specific domains, including beliefs about political preferences, religious views, and even relatively trivial issues such as etiquette (Brandt et al., 2015; Hopkin, Hoyle, \& Toner, 2014; Jongman-Sereno, Raimi, Diebels, \& Leary, 2015; Raimi et al., under review.; Toner et al., 2013). Most relevant to environmental moral exporting, belief superiority has been explored in the environmental domain as well (environmental belief superiority; EBS), with those endorsing more extreme views on everything from climate change, to energy independence, to general protection of the environment reporting higher levels of superiority about those views (Raimi \& Leary, 2014).

No research has yet tested whether those high in environmental belief superiority are particularly likely to try to convert other people to their preferred belief and behaviors. Belief superiority is primarily concerned with how one thinks about their views in relation to 
alternatives rather than how one acts on those views. Yet the research on interpersonal effects of belief superiority suggests that such influence attempts may exist, and may often end badly. Both general and domain-specific belief superiority are associated with negative outcomes during disagreements. For example, those who feel superior about their views on hydraulic fracturing (fracking) report a pronounced willingness to discuss fracking while simultaneously derogating the personality traits of issue opponents (Raimi \& Leary, 2014). High general belief superiority is also associated with negative outcomes during moments of conflict with relationship partners, including experiences of frustration and behaviors such as trying to win arguments at all costs and being unwilling to compromise (Raimi et al., under review). Furthermore, those high in belief superiority engage in motivated reasoning: They are less likely to integrate information from external sources into their own estimations and are more likely to use new information - even contradictory information - to bolster their certainty about their existing beliefs (Brandt et al., 2015; Raimi \& Leary, 2014).

\subsection{Current Research}

The goal of the current research was to explore the understudied topic of peer-to-peer persuasion about environmental issues. In particular, we were interested in who tries to influence the environmental behaviors of others. To do so, we wanted to differentiate between two underexplored individual differences in environmental persuasion: environmental moral exporting (EME) and environmental belief superiority (EBS). Because there is currently no measure of environmental moral exporting, in the first study we created a measure of environmental moral exporting and explored the factor structure of the measure through use of both exploratory and confirmatory factor analyses. In the second study, we examined how environmental moral exporting and environmental belief superiority relate to each other, as well 
as to theoretically related constructs, including general moral exporting and general belief superiority, Big-Five personality traits, attitude characteristics, political ideology, and social corrective measures. We also linked environmental moral exporting and environmental belief superiority, including their interaction, to individuals' reported conversational experiences, selfreported efforts to influence others' environmental behaviors, and the perceived effectiveness, and one's willingness, to confront environmental transgressors.

If environmental moral exporting and environmental belief superiority are both related to conversational attempts as hypothesized, then we would also expect a relationship between each and extraversion. Either environmental moral exporting or environmental belief superiority could relate to other Big-Five traits such as openness to experience or agreeableness (McCrae \& Costa, 1987), but the direction of these potential associations is less clear.

Environmental moral exporting and environmental belief superiority may also relate to environmental attitude characteristics (e.g., attitude clarity and correctness; Cheatham \& Tormala, 2015) and political ideology. Both environmental moral exporting and environmental belief superiority should be related to environmental attitude strength, correctness, and clarity. However, given its moral underpinnings, environmental moral exporting should be more strongly linked to moral convictions about environmental issues (Wisneski, Lytle, \& Skitka, 2009). Given past research (Brandt et al., 2015; Raimi et al., under review; Toner et al., 2013), we expected that there would be a curvilinear relationship between political ideology and environmental belief superiority, and wanted to test whether a similar relationship would emerge between political ideology and environmental moral exporting. With its focus on being unresponsive to others' viewpoints, environmental belief superiority should be more strongly linked to self-righteousness (Falbo \& Belk, 1985) and dogmatism (Altemeyer, 2002) as 
compared to environmental moral exporting. However, we also expected that environmental moral exporting would relate to social vigilantism more strongly than environmental belief superiority does (Saucier \& Webster, 2010).

Despite their similarities, these two individual differences may lead people to distinct approaches to influencing others, and to different experiences while engaging others in environmental conversation. Environmental belief superiority focuses on self-enhancing thoughts, rather than the moral imperative to change minds suggested with environmental moral exporting. Therefore, though we expected that both environmental moral exporting and environmental belief superiority would predict self-reported efforts to influence others' behaviors, we thought this would be particularly likely for individuals who were high in environmental moral exporting. We also thought that the tenor of these conversations may differ based on environmental moral exporting and environmental belief superiority levels. Whereas a successful exporting of one's moral views requires some dialogue with persuasion targets, thinking one's views are superior requires no such accommodation or patience. Thus, we expected that people high in environmental moral exporting would be more likely to stick to environmental conversations and become less frustrated with the conversational experience, as compared to those high in environmental belief superiority. Finally, we expected both environmental moral exporting and environmental belief superiority to correlate with the perceived effectiveness of confronting environmental transgressors and one's willingness to do so (Nolan, 2013), although environmental moral exporting may be more strongly relate to these outcomes compared to environmental belief superiority.

\section{Study 1: Measuring the Environmental Moral Exporting Construct}


Before studying these hypothesized relationships between environmental moral exporting, environmental belief superiority, and related constructs, we first had to create an EME measure. Using two different samples, we used this new measure to explore whether EME captures one construct or many, as well as its statistical properties.

\subsection{Method}

\subsubsection{Participants}

2.1.1.1. Sample 1. Participants for the initial creation of the EME measure were 158 undergraduates (104 women, 54 men; mean age $=19.61, S D=2.36$ ) at a large public university in the Midwestern United States. Participants received partial course credit for participation. A majority of participants identified as White (66\%), though some identified as African American (5\%), Asian (29\%), Latino (1\%), Native American (2\%), or another race (2\%).

2.1.1.2. Sample 2. Sample 2 participants were 166 undergraduates (116 women, 35 men, 15 did not report gender; mean age $=20.13, S D=2.81$ ) from the same large public university in the Midwestern United States. Participants received partial course credit for study involvement. A majority of participants identified as White (71\%), though some identified as African American (6\%), Asian (22\%), Latino (4\%), or another race (3\%).

\subsubsection{Procedure}

For Sample 1, we originally generated eight items to capture the EME construct. Items were based off of the general moral exporting scale (Peterson et al., 2009), with some items that were direct adaptations of original items and some that were new, but nevertheless inspired by the GME measure. Participants indicated the extent to which they agreed with each item using a 1 ("strongly disagree") to 7 ("strongly agree") response scale (the items can be found in Table 1). An initial factor analysis revealed that one item cross-loaded more strongly on a separate, second 
factor. Given the initial eigenvalue and scree plots results for the model, as well as the conceptual impetus for development of the scale, we removed that one item and we then ran a new exploratory factor analysis.

Sample 2 participants only reported their responses to the seven-item EME scale. Given that we developed only eight original environmental moral exporting items and expected a single factor, we believed that we had adequate power to effectively conduct factor analyses. For example, scholars have argued that a ratio of sample size divided by the number of items analyzed should be at least 10 (Everitt, 1975). Our ratio was 19.75 for the exploratory factor analysis, and 20.75 for the confirmatory factor analysis. Others suggest a sample size of 100300, depending on the level of communality (MacCallum, Widaman, Zhang, \& Hong, 1999). Given these heuristics and our sample sizes, we proceeded with running exploratory and confirmatory factor analyses.

\subsection{Results and Discussion}

\subsubsection{Sample 1}

We first investigated the factor structure of the seven EME items, as well as other psychometric properties of EME using data from Sample 1. We ran a principal-axis factor analysis with a promax rotation (see Table 1 for the items and factor loadings). We report results for the largest four factors, first reporting the eigenvalue, followed (in parentheses) by the cumulative percent variance accounted for: $3.82(55 \%), 0.86(67 \%), 0.69(77 \%), 0.56(85 \%)$. Additionally, the scree plot clearly suggested one factor (Cattell, 1966). As a whole, results indicated that all seven items loaded onto one overall EME factor. We also found that the scale had a high level of internal consistency (Cronbach's $\alpha=.87 ; M=3.26, S D=1.12$ ).

\subsubsection{Sample 2}


Using SPSS AMOS (v23.0.0), we ran three confirmatory factor models, comparing fit statistics among the models. We expected that the one-factor seven-item scale that emerged from our exploratory factor analysis in Sample 1 would indicate a good fit in the confirmatory factor analysis (Model 1). We also ran this model with all missing data removed (final $N=150$; Model 2), as well as an optimized model that allowed correlation between strongly related EME items (Model 3).

We compared models according to a number of fit statistics. Our proposed model with one factor and seven items had adequate model fit: Model 1; $\chi^{2}(14, N=166)=23.26, p=.06, \chi^{2}$ / $\mathrm{df}=1.66, \mathrm{RMSEA}=.06, \mathrm{CFI}=.98$, and $\mathrm{AIC}=65.26$. The model with no missing data was also an adequate fit for the data: Model $2 ; \chi^{2}(14, N=150)=22.60, p=.07, \chi^{2} / \mathrm{df}=1.61$, $\mathrm{RMSEA}=.06, \mathrm{CFI}=.98$, and $\mathrm{AIC}=64.60$. Model 3-which allowed for correlations between the items - is shown in Figure 1 and led to the best fitting model: $\left(\chi^{2}(12, N=150)=10.43, p=\right.$ $.58, \chi^{2} / \mathrm{df}=0.87, \mathrm{RMSEA}=.00, \mathrm{CFI}=1.00$, and AIC $=42.43$. Finally, the EME scale again demonstrated a high level of internal consistency (Cronbach's $\alpha=.87 ; M=3.57, S D=1.19$ ).

The findings from our EFA and CFA provided evidence that the seven items of the EME scale form a single factor. This early support for the EME scale gave us confidence that the environmental moral exporting individual difference was worthy of further exploration.

\section{Study 2: Exploring Environmental Moral Exporting, Environmental Belief Superiority, and Peer Influence}

Study 1 demonstrated that we had developed a reliable set of environmental moral exporting items. We next sought to place these EME and EBS within the nomological net of existing peer influence constructs using a more diverse sample of individuals. We expected that the EME and EBS measures would be correlated, that EME and EBS would both relate to 
extraversion. Furthermore, we thought these measures might correlate in different ways with existing social corrective measures. For example, we expected that EBS, but not EME, would relate to self-righteousness, whereas EME, but not EBS, would more closely relate to social vigilantism. We also expected that EME may relate to more self-reported two-way conversational approaches, and EBS would relate more to efforts to dictate and control environmental conversations. Finally, we also expected that EME and EBS would relate to selfreported environmental peer persuasion efforts.

\subsection{Method}

\subsubsection{Participants and Procedure}

Participants were 295 adults ( 166 females, 128 males, 1 unknown; mean age $=34.32, S D$ = 10.87) from MTurk (Buhrmester, Kwang, \& Gosling, 2011; Paolacci \& Chandler, 2014). Most participants identified as White (82\%), but participants also identified as African-American (9\%), Asian (7\%), Pacific Islander ( $<1 \%)$, or American Indian or Alaskan Native (3\%); 9\% of participants identified as Latino. We used an online survey to measure participants' responses to the EME, EBS, and related measures.

\subsubsection{Measures}

Environmental moral exporting. Environmental moral exporting was captured with the seven-item EME scale. The EME had a comparable internal consistency ( $\alpha=.86)$, mean (3.22), and standard deviation (1.26) to the preceding studies.

Environmental belief superiority. Environmental belief superiority was captured with the nine-item EBS scale (Raimi \& Leary, 2014). Participants indicated the extent to which they agreed with each item using a 1 ("no more correct than other viewpoints") to 5 ("totally correct (mine is the only correct view)") response scale ( $\alpha=.95 ; M=2.65, S D=1.16$; e.g., "In your 
view, how much more correct are your beliefs about each of the following issues than other beliefs about these issues? My views on climate change are:").

General moral exporting. General moral exporting was captured with the four-item moral exporting scale (Peterson et al., 2009). Participants indicated the extent to which they agreed with each item using a 1 ("strongly disagree") to 7 ("strongly agree") response scale ( $\alpha=$ $.82 ; M=2.84, S D=1.36$; e.g., "When I meet someone who doesn't share the moral values that are important to me, I take the time to explain my views in an effort to convince them that they are worth living by").

General belief superiority. General belief superiority was captured with the six-item GBS scale (Raimi et al., under review). Participants used the same response scale as with the EBS measure $(\alpha=.84 ; M=2.48, S D=0.98$; e.g., "In your view, how much more correct are your beliefs about each of the following issues than other beliefs about these issues? My views on chain vs. independent restaurants are:").

Big-Five personality traits. Participants completed the Big-Five Inventory (BFI; John \& Srivastava, 1999), which measures each of the Big-Five personality traits (i.e., agreeableness, conscientiousness, extraversion, neuroticism, and openness). Participants used a scale ranging from 1 ("disagree strongly") to 7 ("agree strongly") to report how well various characteristics applied to themselves. Number of items, internal consistency, means, and standard deviations were as follow: agreeableness (nine items; $\alpha=.83 ; M=2.72, S D=0.74$; e.g., "I see myself as someone who is helpful and unselfish with others"); conscientiousness (nine items; $\alpha=.85 ; M=$ $2.82, S D=0.73$; e.g., "I see myself as someone who does a thorough job"); extraversion (eight items; $\alpha=.89 ; M=1.94, S D=0.93$; e.g., "I see myself as someone who is talkative"); neuroticism (eight items; alpha $=.84 ; M=1.70, S D=1.03$; e.g., "I see myself as someone who is 
depressed, blue"); and openness (10 items; $\alpha=.84 ; M=2.65, S D=0.71$; e.g., "I see myself as someone who is original, comes up with new ideas").

Environmental attitude strength. We adapted an existing attitude strength item (Wisneski et al., 2009) to focus on the strength of one's attitudes toward environmental issues. Participants indicated how strongly they felt about their attitudes towards environmental issues using a 1 ("not at all”) to 5 ("extremely") response scale $(M=2.50, S D=1.08$; i.e., "How strongly do you feel about your attitudes towards environmental issues?”).

Environmental attitude correctness/clarity. We adapted existing attitude correctness/clarity items (Cheatham \& Tormala, 2015) to instead focus on one's attitudes toward environmental issues. Participants indicated the extent to which they agreed with items using a 1 ("not at all") to 9 ("very much") response scale; attitude correctness consisted of three items ( $\alpha=$ $.92 ; M=6.01, S D=2.16$; e.g., "How certain are you that your attitudes on environmental issues are the correct attitudes to have?"; see Appendix for all items) and attitude clarity consisted of four items ( $\alpha=.97 ; M=6.48, S D=2.08$; e.g., "How certain are you that you know what your true attitudes are on environmental issues?"; see Appendix for all items).

Moral conviction regarding environmental issues. We adapted existing moral conviction items (Wisneski et al., 2009) to focus on one's moral convictions surrounding environmental issues. Participants indicated the extent to which they agreed with two items using a 1 ("not at all") to 5 ("extremely") response scale ( $\alpha=.89 ; M=3.43, S D=1.05$; e.g., "To what extent are your positions on environmental issues deeply connected to your beliefs about fundamental right and wrong?"; see Appendix for both items).

Political ideology. Participants reported their political ideology, ranging from strongly conservative (1) to strongly liberal (5). 
Social vigilantism. Participants reported their general efforts to influence society, captured with the 14-item social vigilantism scale (Saucier \& Webster, 2010). Participants indicated the extent to which they agreed with each item using a 1 ("disagree very strongly") to 9 ("agree very strongly") response scale ( $\alpha=.89 ; M=5.09, S D=1.54$; e.g., "I feel as if it is my duty to enlighten other people").

Self-righteousness. Participants reported their own self-righteousness, captured with the four-item self-righteousness scale (Falbo \& Belk, 1985). Participants indicated the extent to which they agreed with each item using a 1 ("disagree very strongly") to 9 ("agree very strongly") response scale ( $\alpha=.46 ; M=3.50, S D=1.26$; e.g., "People who disagree with me are wrong").

Dogmatism. Participants reported how willing they were to question their opinions, captured with the 20-item dogmatism scale (Altemeyer, 2002). Participants indicated the extent to which they agreed with each item using a 1 ("strongly disagree") to 9 ("strongly agree") response scale ( $\alpha=.89 ; M=2.59, S D=0.63$; e.g., "Anyone who is honestly and truly seeking the truth will end up believing what I believe").

Self-reported conversational experiences. Participants reported their conversational experiences when talking to others about environmental issues. Participants responded to nine items using a 1 ("strongly disagree") to 7 ("strongly agree") response scale (e.g., "When talking to others about environmental issues, I often get impatient"; see Appendix for all items).

Self-reported past efforts to influence others' environmental behaviors. Participants reported their past efforts to influence the environmental behavior of others, including through conversation, persuasion attempts, and modeling of environmental behavior. Participants indicated the extent to which they had engaged in each behavior when they had a chance, 
responding to nine items using a 0 ("never") to 6 ("always") response scale (e.g., "During the past month, I talked about environmental issues generally with other people"; see Appendix for all items).

Perceived effectiveness of confronting environmental transgressors. We adapted the perceieved effectivness of confronting environmental transgressors scale to refer to environmental behavior generally, instead of the original littering focus (four items; Nolan, 2013). Participants indicated the extent to which they agreed with each item using a 1 ("have no effect") to 4 ("very effective") response scale ( $\alpha=.68 ; M=2.34, S D=0.70 ;$ e.g., "How effective do you believe each of the following strategies would be at increasing other people's environmentally-friendly behaviors: Handing out coupons to people who engage in environmentally-friendly behaviors"; see Appendix for all items).

Willingness to confront environmental transgressors. We adapted the willingness to confront environmental transgressors scale to refer to environmental behavior generally, instead of the original littering focus (four items; Nolan, 2013). Participants indicated the extent to which they agreed with each item using a 1 ("very unwilling”) to 6 ("very willing") response scale $(\alpha=.76 ; M=3.68, S D=1.27$; e.g., "How willing would you be to implement each of the following strategies to promote environmentally-friendly behaviors: Handing out coupons to people who engage in environmentally-friendly behaviors"; see Appendix for all items).

Demographics. Participants reported their age, gender, race/ethnicity, family income, and education level.

\subsection{Results and Discussion}

\subsubsection{Correlations between EME, EBS, and related constructs}


$\boldsymbol{E M E}$ and $\boldsymbol{E B S}$. We first examined correlations between the environmental and general versions of moral exporting and belief superiority (see Table 2), finding that people high on EME were high on GME and people high on EBS were high on GBS. Furthermore, people high on EME also tended to be higher on EBS.

Big-Five personality traits. We next turned to correlations between EME, EBS, and the Big-Five. As expected, people high in extraversion were more likely to be higher in both EME and EBS. People high on EME (but not those high on EBS) were also higher on agreeableness, conscientsciousness, and openness to experience. The lack of correlation between openness and EBS replicates previous research on these constructs (Raimi \& Leary, 2014). Meanwhile, people high on EBS were lower on neuroticism, although no such relationship emerged with EME.

Attitude characteristics. We next tested correlations between EME, EBS, and attitude characteristics (see Table 3). We found that people high in either EME or EBS reported that they felt more strongly about their environmental attitudes, they held stronger beliefs in the correctness of their attitudes, and they stated that they clearly knew their own attitudes. People high in EME also reported holding a moral conviction about environmental issues; this was also true for people high EBS, though less so compared to EME.

Political ideology. We next used regressions to test whether EME and EBS are related to political ideology, either in a linear direction or in a curvilinear pattern whereby those with more extreme political ideology tend to feel more superior about their views or tend to try to persudae others. Following the technique outlined by Toner et al. (2013), we ran two regressions in which the linear effect of political ideology was entered in Step 1 of the model, and the quadratic effect was added in Step 2. First, this overall model was used to predict EBS. There was not a linear effect of ideology on EBS. However, as in all other previously published belief superiority 
studies, there was a significant quadratic effect, $(b=.18, S E=.05, C I=.08, .28, p<.001)$, such that people with more extreme ideology (liberal or conservative) were more likely to report being higher in EBS. Next, we used this model to test the effect of linear and quadratic attitudes on EME. There was a linear effect of ideology on $\operatorname{EME~}(b=.26, S E=.07, C I=.13, .40, p<.001)$, but this effect was not qualified by a quadratic effect $(p>.05)$. Thus, only liberals reported being higher on EME.

Social corrective measures. We next turned to correlations between EME, EBS, and social corrective measures: social vigilantism, self-righteousness, and dogmatism. We found that people high in EME reported being higher in all of the social corrective measures except selfrighteousness. People high in EBS were also high in all of the social correctiveness measures, including self-righteousness. Furthermore, the relationship between dogmatism and EBS was stronger than the correlation between dogmatism and EME.

\subsubsection{Self-reported conversational experiences related to EME and EBS}

We examined the factor strucure of the nine conversational experience items. Exploratory factor analysis suggested that there were four separate factors related to environmental conversational experiences (eigenvalues > 1.0): willingness to engage in two-way conversations (two items; $\alpha=.86$ ), feelings of pessimism or frustratation about conversations (four items; $\alpha=.75$ ), confidence in one's knowledge during conversations (two items; $\alpha=.59$ ), and enjoyment of conversations (one item).

We used four regressions to test the effects of EME, EBS, and their interaction on each of the four self-reported conversational subscales (see Table 4). Results showed that people high in EME were more willing to engage in two-way conversations; in contrast, people high in EBS were unenthusiastic about two-way discussions. However, people high in either EME or EBS 
tended to feel pessimistic and frustrated during conversations. People high in EBS, but not those high in EME, were marginally more sure of their knowledge in environmental conversations than people low in those constructs. Finally, people high in EME, but not those high in EBS, reported relatively more enjoyment of environmental conversations. For all interactions, we meancentered the predictors, entered the main effects in the first step, and entered the interaction in the second step. We did not find any evidence that the interaction between EME and EBS predicted any of the conversational experiences.

\subsubsection{Self-reported behavioral implications of EME and EBS}

Self-reported past efforts to influence others' environmental behaviors. We conducted an initial factor analysis on the nine items measuring self-reported past efforts to influence others' environmental behaviors, finding that all of the items formed a single factor. A composite variable was created using the mean of these items $(\alpha=.95 ; M=1.77, S D=1.55)$. A regression on this composite (see Table 5) found that people high in EME were more likely to have tried to influence others' behaviors in the past, as were people high in EBS; the interaction between EME and EBS did not predict past efforts to influence others' behaviors.

Perceived effectiveness of confronting transgressors in the future. People high in EME believed it would be effective to confront transgressors. In contrast, those high in EBS did not believe it would be particularly effective to confront transgressors. Likewise, the interaction between EME and EBS did not predict effectiveness ratings.

Willingness to confront transgressors in the future. People high in EME were also more willing to confront transgressors, whereas those high in EBS were not. However, the interaction between EME and EBS qualified this main effect. Analysis of the simples slopes revealed that individuals high in EME $(+1 S D)$ did not vary in their willingness-to-confront 
according to $\operatorname{EBS}(b=.04, t=0.64, p=.52, d=.08, \hat{\mathrm{y}}$ at $-1 S D$ of EBS $=4.38, \hat{\mathrm{y}}$ at $+1 S D$ of EBS $=4.49)$. In contrast, individuals who were low in EME $(-1 S D)$ did vary $(b=-.16, t=-2.05, p=$ $.04, d=.24 ; \hat{\mathrm{y}}$ at $-1 S D$ of $\mathrm{EBS}=2.99, \hat{\mathrm{y}}$ at $+1 S D$ of $\mathrm{EBS}=2.62$ ), such that people who were low in EME and high in EBS were the least willing to confront transgressors. Thus, people high in EME, regardless of EBS, were more likely to be willing to confront transgressors, as compared to people low in EME and high in EBS.

We ran additional analyses to explore how controlling for other measures (i.e., vigilantism, self-righteousness, and dogmatism) affected the relationships between EME, EBS, and the conversational and behavioral outcomes outlined previously. Although some minor variations in the results emerged (e.g., EBS was no longer a significant predictor of past efforts, $p=.10$; EBS became a significant predictor of conversational confidence, $p=.01$ ), the overall trend in effects was largely unchanged. ${ }^{1}$

We also tested whether controlling for GME and GBS affected the findings. In general, the EME scale remained a significant predictor of the outcomes when controlling for GME. However, environmental belief superiority sometimes emerged as a newly significant predictor of certain outcomes when controlling for GBS. For example, whereas EBS was not a significant predictor of participants' perceived effectiveness of confronting transgressors when only examined with EME in the model, it became a significant negative predictor of perceived effectiveness $(p=.002)$ when the model included GBS. Conversely, EBS was no longer a

\footnotetext{
${ }^{1}$ We also controlled for demographics, with no change to the results. Demographics rarely correlated with EME, EBS, or the conversational and behavioral outcomes. The lack of a relationship between gender and EBS is in contrast with other work finding a consistent pattern whereby men are higher in belief superiority than women (Raimi et al., under review).
} 
significant predictor of past efforts to influence others $(p=.84)$ or being unenthusiastic about engaging in two-way conversations $(p=.54)$ when controlling for GBS.

In sum, we found that EME and EBS were moderately related to each other, and that they both were linked to self-reported extraversion. Both measures also predicted theoretically similar constructs such as attitude correctness, attitude clarity, and self-reported social corrective measures. Despite these similarities, results from Study 2 also demonstrated clear differences between EME and EBS. Those high in EBS have been found to be willing to discuss environmental issues, though the nature of that discussion was left unclear in previous research (Raimi \& Leary, 2014). Our results suggest that people high in EBS prefer to engage in conversations in which they are imparting knowledge to others, rather than conversations in which there is true give-and-take. People high in EME, on the other hand, may be more likely to promote dialogue (as opposed to simply monologue) or at least recognize that converting others to one's own environmental viewpoints requires the winning of hearts and minds rather than simply the winning of arguments.

\section{General Discussion}

\subsection{Who attempts to influence others' environmental behaviors?}

Traditional research on environmental behavior has explored the predictors of behavior change as a function of researcher efforts, and on occasion the factors linked to environmental peer persuasion (Connor et al., 2016; Geiger \& Swim, 2016; Nolan, 2013; Southwell \& Murphy, 2014). The current research examines self-reported environmental behavior outside of these contexts, and in particular demonstrates the value in asking who attempts to influence the environmental behaviors of their peers. Toward such a goal, we introduced and validated a measure of a newly identified construct: environmental moral exporting. 
We also found that people high in environmental moral exporting (but not environmental belief superiority) were likely to be high in agreeableness, openness to experience, and conscientiousness. These results mirror research linking openness to pro-environmental beliefs (Brick \& Lewis, 2016; Markowitz, Goldberg, Ashton, \& Lee, 2012). These personality traits are also generally consistent with the self-reported conversational experiences of people high in environmental moral exporting, in particular the desire for two-way dialogue. People high in environmental belief superiority, meanwhile, were particuarly low in neuroticism, perhaps revealing the unexpected benefits of belief in the superiority of one's views. Both people high in environmental moral exporting and environmental belief superirority were high in extraversion, which converges with evidence that both types of people attempt to influence the environmental behaviors of others. Given the conversational experiences reported, though, perhaps people high in environmental belief superiority prefer to try to influence the environmental behaviors of others through non-conversational routes when possible, such as modeling of behavior or posting their views on social media sites where two-way interaction is less likely.

Past research has found that conservatives tend to be higher in general moral exporting compared to liberals (Peterson et al., 2009), but we found that liberals tended to be higher in environmental moral exporting. This linear relationship suggests that whereas environmental moral exporting does not inherently require people's attitudes to be pro- or anti-environment, in practice liberals tend to be more willing to export their environmental moral beliefs. This is a notable departure from previous findings, and suggests that the appeal of moral exporting to different groups of individuals may vary by domain. Consistent with prior research, however, we did find a curvilinear relationship between political ideology and environmental belief superiority (Brandt et al., 2015; Raimi et al., under review.; Toner et al., 2013), such that people 
on both ends of the political spectrum were more likely to report belief superiority compared to people more moderate in their political views.

Environmental moral exporting and environmental belief superiority both related to selfreported efforts to influence the environmental behaviors of others, albeit in different ways. People high in moral exporting were more active in their efforts to influence the environmental behaviors of others, preferred a two-way dialogue between individuals, and enjoyed such interactions more. In contrast, individuals high in environmental belief superiority preferred to put less effort into influencing others, compared to those high in environmental moral exporting, and tended to avoid environmental conversations. When individuals high in environmental belief superiority did have those conversations, they were likely to get frustrated (as were people high in environmental moral exporting) and to be marginally more certain of their knowledge.

Although the current research specifically focuses on environmental applications of moral exporting and belief superiority, the underlying constructs are likely at work in a variety of other domains. For example, it is worth noting that the relationship between environmental belief superiority and relevant outcomes occasionally shifted when general belief superiority was included in the models. Future research should expand on this work by teasing apart which correlates of environmental moral exporting and environmental belief superiority are due to general tendencies to believe one's beliefs are superior or export one's morals to others, and which correlates are unique to environmental topics.

The current research also relates to the literature on persuasion resistance, and in particular the strategies people use to decrease the likelihood that they are influenced by others (e.g., Jacks \& Cameron, 2003; Saucier, Webster, Hoffman, \& Strain, 2014). Efforts at persuasion by people high in environmental moral exporting or environmental belief superiority 
may backfire by eliciting resistance strategies in their peers, such as negative affect, counterarguing, or source derogation. Thus, whereas the goal may be to persuade their peers, the result of these efforts may be an increase in resistance to such persuasion. Future research should consider this dyadic perspective on environmental persuasion efforts and resistance.

\subsection{Limitations}

A number of shortcomings exist with the present research. Relying on self-reported environmental behavior somewhat limits our confidence in whether people high in environmental moral exporting or environmental belief superiority truly try to influence people, and likewise whether people have accurate assessments of their conversational interactions. Prior meta-analytic research has found that, on average, self-reported and objective behavior is only moderately correlated ( $r=.46$; Kormos \& Gifford, 2014). It may be that people high in environmental moral exporting, for example, want to believe that they take a two-way conversational approach to dialogue with others, while their conversation partners may actually perceive the efforts as hostile or domineering. Future research should test these ideas during actual conversations, such as dyadic interactions in the lab. This work could then consider how others perceive these efforts and which persuasion approaches are actually effective in this context, including whether efforts lead to simple short-term compliance or long-term internalization of beliefs and values (Kelman, 2006).

It is also possible that participants in these studies were inaccurate in their self-reports of persuasion attempts, and some measurements of behaviors may be more biased by self-reporting than others. For example, people may accurately self-report how frequently they engage in less confrontational efforts to influence the environmental behaviors, such as through modeling of behavior, and overestimate other, more confrontational efforts such as persuasion efforts. 
Research on self-enhancement tendencies also suggests that people may be overly optimistic about their success in these peer persuasion situations (Dunning, Johnson, Ehrlinger, \& Kruger, 2003; Leary \& Toner, 2012). Finally, two of the scales had low reliabilities (self-righteousness and the perceived effectiveness of confronting transgressors), which may have attenuated their correlations with other scales.

\subsection{Future directions and conclusion}

The relationship between environmental moral exporting and environmental belief superiority deserves further exploration. Though regression analyses revealed clear differences in perceived ability to predict relevant outcomes, we do not wish to suggest that these are entirely distinct constructs; indeed, they correlated with one another. Future work should tease apart the ways in which these two constructs relate to and influence each other. The interaction between environmental moral exporting and environmental belief superiority also deserves further consideration, as we found evidence that people low in environmental moral exporting but high in environmental belief superiority were least likely to confront environmental transgressors. There may be something unique about people who are simultaneously high in environmental belief superiority and low in environmental moral exporting. Perhaps these individuals have all the self-righteous anger about their position that is associated with environmemental belief superiority, but lack the optismism about the effectivenss of such confrontations and enjoyment of conversations that are uniquely associated with environmental moral exporting.

Experimental contexts would also be valuable to consider, as it would be interesting to see how people high or low in environmental moral exporting or environmental belief superiority react to various environmental messages or news stories. This approach would help us 
understand why people high in environmental moral exporting or environmental belief superiority choose to engage with others on environental issues in the first place. For example, people high in environmental moral exporting, but not environmental belief superiority, may adopt more of an action orientation in response to perceived environmental dangers or injustices that are communicated in a news story. Additionally, determining whether people high in environmental moral exporting draw upon the behavior change strategies that they notice in common environmental messaging efforts, and proceed to use those strategies when talking to others, would help us appreciate when and how behavior change interventions lead people to influence the environmental behaviors of those around them. Finally, the present work did not measure or vary the receipient of participants' influence efforts. People may approach influencing family members differently than friends or even strangers. Future work should consider these relationship dimensions and how they affect influence strategies.

Understanding the individual differences that underlie environmental peer persuasion is a key component of success in environmental communication. There are whole professions that depend on the willingness and ability of people to talk to others about environmental issues, such as park rangers, environmental canvassers, and even home energy auditors. Knowing how people differ in environmental moral exporting and environmental belief superiority will help to recruit and aid employees and volunteers who are particularly well-suited to these sorts of peerpersuasion professions. Beyond the professional implications, however, understanding these individual differences will help lay people promote more effective environmental conversations with their family and friends, engage others in the classroom, communicate on social media, and discuss environmental issues at the Thanksgiving dinner table. 


\section{Appendix}

\section{Attitude correctness/clarity}

When it comes to environmental issues:

1. How certain are you that you know what your true attitudes on environmental issues?

2. How certain are you that the attitudes you express on environmental issues really reflect your true thoughts and feelings?

3. To what extent are your true attitudes on environmental issues clear in your mind?

4. How certain are you that the attitudes you expressed environmental issues are really the attitudes you have?

5. How certain are you that your attitudes environmental issues are the correct attitudes to have?

6. To what extent do you think that other people should have the same attitudes as you on environmental issues?

7. How certain are you that of all of the possible attitudes one might have environmental issues, your attitudes reflects the right way to think and feel about these issues?

\section{Environmental moral conviction}

Please respond to each question below.

1. To what extent are your positions on environmental issues deeply connected to your beliefs about fundamental right and wrong?

2. To what extent does your attitude about environmental issues reflect something about your core moral values?

\section{Environmental conversational experiences}

Willingness to engage in two-way conversations

1. When talking to others about environmental issues, I let them respond to my points.

2. When talking to others about environmental issues, I try to have a two-way conversation.

Frustration during conversations

1. When talking to others about environmental issues, I often get impatient.

2. When talking to others about environmental issues, I think that my views are better than other people's.

3. When talking to others about environmental issues, I think they would benefit from knowing what I do about the topic.

4. When talking to others about environmental issues, I often feel frustrated.

Confidence of environmental knowledge during conversations

1. When talking to others about environmental issues, I often end the conversation with a different opinion than when I started.

2. When talking to others about environmental issues, I often feel uninformed.

Enjoyment of environmental conversations

1. I enjoy talking to others about environmental issues. 


\section{Past efforts to influence others' environmental behaviors}

1. During the past month, I talk about environmental issues generally with other people

2. During the past month, I engaged in environmental behaviors in places where other people saw or knew that I engaged in them

3. During the past month, I tried to persuade other people to engage in environmental behaviors

4. During the past month, I tried to teach other people how to engage in environmental behaviors

5. During the past month, I brought up environmental behaviors in conversations with other people

6. During the past month, I emailed friends or family members about environmental behaviors

7. During the past month, I posted about environmental behaviors on social media (on Facebook, Twitter, etc.)

8. During the past month, I posted about environmental behaviors on comment sections of internet newspaper stories or blogs

9. During the past month, I tried to get other people to adopt my environmental values

\section{Perceived effectiveness of confronting environmental transgressors}

How effective do you believe each of the following strategies would be at increasing other people's environmentally-friendly behaviors?

1. Handing out coupons to people who engage in environmentally-friendly behaviors

2. Smiling at people who engage in environmentally-friendly behaviors

3. Asking students to pay a small fine for behaviors that harm the environment

4. Frowning at people who engage in behavior that harm the environment

\section{Willingness to confront environmental transgressors}

How willing would you be to implement each of the following strategies to promote environmentally-friendly behaviors?

1. Handing out coupons to people who engage in environmentally-friendly behaviors

2. Smiling at people who engage in environmentally-friendly behaviors

3. Asking students to pay a small fine for behaviors that harm the environment

4. Frowning at people who engage in behaviors that harm the environment 


\section{References}

Altemeyer, B. (2002). Dogmatic behavior among students: testing a new measure of dogmatism. The Journal of Social Psychology, 142, 713-721. doi: 10.1080/00224540209603931

Aronson, E., \& Gonzales, M. H. (1990). Alternative social influence processes applied to energy conservation. In J. Edwards, R. S. Tindale, L. Heath, \& E. J. Posavac (Eds.), Social influence processes and prevention: Social psychological applications to social issues (pp. 301-325). New York, NY: Springer. doi: 10.1007/978-1-4899-2094-2_13

Asensio, O. I., \& Delmas, M. A. (2015). Nonprice incentives and energy conservation. Proceedings of the National Academy of Sciences, 112, E510-E515. doi: $10.1073 /$ pnas. 1401880112

Bandura, A., Ross, D., \& Ross, S. A. (1963). Imitation of film-mediated aggressive mode. Journal of Abnormal and Social Psychology, 66, 3-11.

Brandt, M. J., Evans, A. M., \& Crawford, J. T. (2015). The unthinking or confident extremist? Political extremists are more likely than moderates to reject experimenter-generated anchors. Psychological Science, 26, 189-202. doi: 10.1177/0956797614559730

Brick, C., \& Lewis, G. J. (2016). Unearthing the "green"personality: Core traits predict environmentally friendly behavior. Environment and Behavior, 48, 635-658. doi: $10.1177 / 0013916514554695$

Brown, M. A. (1984). Change mechanisms in the diffusion of residential energy conservation practices: an empirical study. Technological Forecasting and Social Change, 25, 123-138. doi: $10.1016 / 0040-1625(84) 90087-8$

Buhrmester, M., Kwang, T., \& Gosling, S. D. (2011). Amazon's Mechanical Turk: A new source of inexpensive, yet high-quality, data? Perspectives on Psychological Science, 6, 3-5. doi: 


\section{$10.1177 / 1745691610393980$}

Burn, S. M. (1991). Social Psychology and the Stimulation of Recycling Behaviors: The Block Leader Approach. Journal of Applied Social Psychology, 21, 611-629. doi: 10.1111/j.15591816.1991.tb00539.x

Campbell, T. H., \& Kay, A. C. (2014). Solution aversion: On the relation between ideology and motivated disbelief. Journal of Personality and Social Psychology, 107, 809-824. doi: $10.1037 / \mathrm{a} 0037963$

Cattell, R. B. (1966). The Scree Test For The Number Of Factors. Multivariate Behavioral Research, 1, 245-276. doi: 10.1207/s15327906mbr0102_10

Cheatham, L., \& Tormala, Z. L. (2015). Attitude Certainty and Attitudinal Advocacy: The Unique Roles of Clarity and Correctness. Personality \& Social Psychology Bulletin, 41, 1537-50. doi: 10.1177/0146167215601406

Connor, P., Harris, E., Guy, S., Fernando, J., Shank, D. B., Kurz, T., ... Kashima, Y. (2016). Interpersonal communication about climate change: How messages change when communicated through simulated online social networks. Climatic Change, 136, 463-476. doi: $10.1007 / \mathrm{s} 10584-016-1643-\mathrm{z}$

Corner, A., \& Pidgeon, N. (2015). Like artificial trees? The effect of framing by natural analogy on public perceptions of geoengineering. Climatic Change, 130, 425-438. doi: $10.1007 / \mathrm{s} 10584-014-1148-6$

Darley, J. M. (1978). Energy conservation techniques as innovations, and their diffusion. Energy and Buildings, 1, 339-343. doi: 10.1016/0378-7788(78)90013-0

Dunlap, R. E., Liere, K. D. Van, Mertig, A. G., \& Jones, R. E. (2000). Measuring Endorsement of the New Ecological Paradigm : A Revised NEP Scale. Journal of Social Issues, 56, 425- 
442. doi: 10.1111/0022-4537.00176

Dunning, D., Johnson, K., Ehrlinger, J., \& Kruger, J. (2003). Why people fail to recognize their own incompetence. Current Directions in Psychological Science, 12, 83-87. doi: $10.1111 / 1467-8721.01235$

Dwyer, P. C., Maki, A., \& Rothman, A. J. (2015). Promoting energy conservation behavior in public settings: The influence of social norms and personal responsibility. Journal of Environmental Psychology, 41, 30-34. doi: 10.1016/j.jenvp.2014.11.002

Everitt, B. S. (1975). Multivariate Analysis : the Need for Data, and other Problems Multivariate Analysis : the Need for Data, and other Problems. British Journal of Psychiatry, 126, 237240. doi: 10.1192/bjp.126.3.237

Falbo, T., \& Belk, S. S. (1985). A short scale to measure self-righteousness. J Pers Assess, 49, 172-177. doi: 10.1207/s15327752jpa4902_13

Feinberg, M., \& Willer, R. (2012). The moral roots of environmental attitudes. Psychological Science, 24, 56-62. doi: 10.1177/0956797612449177

Geiger, N., \& Swim, J. (2016). Climate of silence: Pluralistic ignorance as a barrier to climate change discussion. Journal of Environmental Psychology. doi: 10.1016/j.jenvp.2016.05.002

Goldstein, N. J., Cialdini, R. B., \& Griskevicius, V. (2008). A Room with a Viewpoint: Using Social Norms to Motivate Environmental Conservation in Hotels. Journal of Consumer Research, 35, 472-482. doi: 10.1086/586910

Hart, P. S., \& Nisbet, E. C. (2012). Boomerang Effects in Science Communication: How Motivated Reasoning and Identity Cues Amplify Opinion Polarization About Climate Mitigation Policies. Communication Research, 39, 701-723. doi:

$10.1177 / 0093650211416646$ 
Hopkin, C. R., Hoyle, R. H., \& Toner, K. (2014). Intellectual humility and reactions to opinions about religious beliefs. Journal of Psychology \& Theology, 42, 50-61.

Jacks, J. Z., \& Cameron, K. A. (2003). Strategies for Resisting Persuasion. Basic and Applied Social Psychology, 25, 145-161. doi: 10.1207/S15324834BASP2502_5

John, O. P., \& Srivastava, S. (1999). The Big Five trait taxonomy: History, measurement, and theoretical perspectives. Handbook of Personality: Theory and Research, 2, 102-138. doi: citeulike-article-id:3488537

Jones, J. M. (n.d.). In U.S., concern about environmental threats eases. Retrieved from http://www.gallup.com/poll/182105/concern-environmental-threats-eases.aspx

Jongman-Sereno, K. P., Raimi, K. T., Diebels, K. J., \& Leary, M. R. (2015). Attitude extremity and belief superiority: Feeling superior about one's trivial attitudes. Under Review.

Kelman, H. C. (2006). Interests, relationships, identities: Three central issues for individuals and groups in negotiating their social environment. Annual Review of Psychology, 57, 1-26. doi: 10.1146/annurev.psych.57.102904.190156

Kormos, C., \& Gifford, R. (2014). The validity of self-report measures of proenvironmental behavior: Ameta-analytic review. Journal of Environmental Psychology, 40, 359-371. doi: 10.1016/j.jenvp.2014.09.003

Leary, M. R., \& Toner, K. (2012). Reducing egoistic bias in self-beliefs. In S. Vazire \& T. D. Wilson (Eds.), The handbook of self-knowledge (pp. 413-438). New York, NY: Guilford Publications.

MacCallum, R. S., Widaman, K. F., Zhang, S., \& Hong, S. (1999). Sample size in factor analysis. Psychol Methods, 4, 84-89.

Markowitz, E. M., Goldberg, L. R., Ashton, M. C., \& Lee, K. (2012). Profiling the "Pro- 
Environmental Individual”: A Personality Perspective. Journal of Personality, 80, 81-111. doi: 10.1111/j.1467-6494.2011.00721.x

McCrae, R. R., \& Costa Jr, P. T. (2008). The five-factor theory of personality. Handbook of Personality: Theory and Research (3rd Ed.). doi: 10.3905/jpe.2000.319978

McCrae, R. R., \& Costa, P. T. (1987). Validation of the five-factor model of personality across instruments and observers. Journal of Personality and Social Psychology, 52, 81-90. doi: $10.1037 / 0022-3514.52 .1 .81$

McDonald, R. I., Chai, H. Y., \& Newell, B. R. (2015). Personal experience and the "psychological distance" of climate change: An integrative review. Journal of Environmental Psychology, 44, 109-118. doi: 10.1016/j.jenvp.2015.10.003

Milfont, T. L., \& Duckitt, J. (2010). The environmental attitudes inventory: A valid and reliable measure to assess the structure of environmental attitudes. Journal of Environmental Psychology, 30, 80-94. doi: 10.1016/j.jenvp.2009.09.001

Nolan, J. M. (2013). Creating a culture of conservation: Willingness to confront environmental transgressors. Ecopsychology, 5, 3-8. doi: 10.1089/eco.2012.0064

Noonan, D. S., Hsieh, L.-H. C., \& Matisoff, D. (2013). Spatial Effects in Energy-Efficient Residential HVAC Technology Adoption. Environment and Behavior, 45, 476-503. doi: $10.1177 / 0013916511421664$

Paolacci, G., \& Chandler, J. (2014). Inside the Turk: Understanding Mechanical Turk as a Participant Pool. Current Directions in Psychological Science, 23, 184-188. doi: $10.1177 / 0963721414531598$

Peterson, B., Smith, J. A., Tannenbaum, D., \& Shaw, M. P. (2009). On the "exporting" of morality: Its relation to political conservatism and epistemic motivation. Social Justice 
Research, 22, 206-230. doi: 10.1007/s11211-009-0101-8

Raimi, K. T., Jongman-Sereno, K. P., \& Leary, M. R. (n.d.). General belief superiority: Correlates, motivations, and interpersonal consequences.

Raimi, K. T., \& Leary, M. R. (2014). Belief superiority in the environmental domain: Attitude extremity and reactions to fracking. Journal of Environmental Psychology, 40, 76-85. doi: 10.1016/j.jenvp.2014.05.005

Rodgers, J. L., \& Rowe, D. C. (1993). Social Contagion and Adolescent Sexual Behavior A Development EMOSA Model. Psychological Review, 100, 479-510.

Saucier, D. a, \& Webster, R. J. (2010). Social vigilantism: measuring individual differences in belief superiority and resistance to persuasion. Personality and Social Psychology Bulletin, 36, 19-32. doi: 10.1177/0146167209346170

Saucier, D. A., Webster, R. J., Hoffman, B. H., \& Strain, M. L. (2014). Social vigilantism and reported use of strategies to resist persuasion. Personality and Individual Differences, 70, 120-125. doi: 10.1016/j.paid.2014.06.031

Schultz, P. W., Nolan, J. M., Cialdini, R. B., Goldstein, N. J., \& Griskevicius, V. (2007). Research Article: The Constructive, Destructive, and Reconstructive Power of Social Norms. Psychological Science, 18, 429. doi: 10.1111/j.1467-9280.2007.01917.x

Schultz, P. W., \& Zelezny, L. (1999). Values As Predictors of Environmental Attitudes: Evidence for Consistency Across 14 Countries. Journal of Environmental Psychology, 19, 255-265. doi: 10.1006/jevp.1999.0129

Southwell, B. G., \& Murphy, J. (2014). Weatherization behavior and social context: The influences of factual knowledge and social interaction. Energy Research and Social Science, 2, 59-65. doi: 10.1016/j.erss.2014.03.019 
Southwell, B. G., Murphy, J. J., DeWaters, J. E., LeBaron, P. A., \& Fitts Willoughby, J. (2014). Energy information sharing in social networks : The roles of objective knowledge and perceived understanding. The Journal of Sustainability Education.

Stern, P. C., \& Raimi, K. T. (2015). Simple mental models for informating climate choices. Social Research: An International Quarterly, 82, 583-608.

Swim, J. K. (2013). Confronting for conservation. Ecopsychology, 5, 1-2. doi: 10.1089/eco.2013.0021

Swim, J. K., \& Bloodhart, B. (2013). Admonishment and praise: interpersonal mechanisms for promoting proenvironmental behavior. Ecopsychology, 5, 24-35. doi: 10.1089/eco.2012.0065

Toner, K., Leary, M. R., Asher, M. W., \& Jongman-Sereno, K. P. (2013). Feeling superior is a bipartisan issue: extremity (not direction) of political views predicts perceived belief superiority. Psychological Science, 24, 2454-62. doi: 10.1177/0956797613494848

Whitmarsh, L., \& O’Neill, S. (2010). Green identity, green living? The role of pro-environmental self-identity in determining consistency across diverse pro-environmental behaviours. Journal of Environmental Psychology, 30, 305-314. doi: 10.1016/j.jenvp.2010.01.003

Wisneski, D. C., Lytle, B. L., \& Skitka, L. J. (2009). Gut reactions: Moral conviction, religiosity, and trust in authority. Psychological Science, 20, 1059-1063. doi: 10.1111/j.14679280.2009.02406.x

Zhang, H., Vorobeychik, Y., Letchford, J., \& Lakkaraju, K. (2016). Data-Driven Agent-Based Modeling, with Application to Rooftop Solar Adoption. Ourenergypolicy.Org. Retrieved from http://www.ourenergypolicy.org/wp-content/uploads/2014/11/abmsolar.pdf 
Table 1

Factor pattern matrix (principal-axis factor analysis, promax rotation) for EME items, Study 1

\begin{tabular}{l}
\hline \multicolumn{1}{c}{ EME items } \\
\hline Factor 1 \\
\hline own views on environmental issues \\
8. I would take time to teach someone how to live their life in a way that is more consistent with my \\
environmental views \\
7. I try to set a good example of proper environmental behavior by engaging in environmental \\
behaviors in front of people or in places where I know they will see that someone has engaged in the \\
environmental behavior in that setting in the past \\
6. People with different cultural backgrounds than I have should still take time to appreciate the views \\
of people like me on environmental issues \\
1. When I meet someone who doesn't share my views on environmental issues that are important to \\
me, I take the time to explain my views in an effort to convince them that my views are worth living by \\
3. I believe that my views on environmental issues are the types of views that the government should \\
look to turn into federal and state policy \\
4. If people disagree with me on environmental issues, then they are wrong and need to change their \\
views
\end{tabular}

Note. $N=156$. EME = environmental moral exporting. An eighth item "I have supported (or would support) organizations that advocate for my views on environmental issues (including membership, giving time, and/or donating money" was excluded because it did not load onto the same factor as the other seven items. 
Table 2

Correlations between EME, EBS, GME, GBS, and Big-Five personality traits, Study 2

\begin{tabular}{|c|c|c|c|c|c|c|c|c|c|}
\hline & 1 & 2 & 3 & 4 & 5 & 6 & 7 & 8 & 9 \\
\hline 1. EME & .86 & & & & & & & & \\
\hline 2. EBS & $.48 * *$ & .95 & & & & & & & \\
\hline 3. GME & $.52 * *$ & $.26 * *$ & .82 & & & & & & \\
\hline 4. GBS & $.38 * *$ & $.76^{* *}$ & $.28 * *$ & .84 & & & & & \\
\hline 5. Agreeableness & $.20 * *$ & -.01 & $.17 * *$ & $-.12 *$ & .83 & & & & \\
\hline 6. Conscientiousness & $.16^{* *}$ & .08 & $.17 * *$ & -.01 & $.53 * *$ & .85 & & & \\
\hline 7. Extraversion & $.21 * *$ & $.20 * *$ & $.20 * *$ & $.21 * *$ & $.32 * *$ & $.30 * *$ & .89 & & \\
\hline 8. Neuroticism & -.09 & $-.16 * *$ & -.08 & -.11 & $-.50 * *$ & $-.53 * *$ & $-.38 * *$ & .84 & \\
\hline 9. Openness & $.23 * *$ & .10 & $.13^{*}$ & -.003 & $.30 * *$ & $.27 * *$ & $.37 * *$ & $-.20 * *$ & .84 \\
\hline
\end{tabular}

Note. ${ }^{*} p<.05 .{ }^{* *} p<.01$. The diagonal of the table lists the respective scale alphas. EME $=$ environmental moral exporting. EBS $=$ environmental belief superiority. GME = general moral exporting. GBS = general belief superiority. 
Table 3

Correlations between EME, EBS, attitude characteristics, and social corrective measures, Study 2

\begin{tabular}{|c|c|c|c|c|c|c|c|c|c|}
\hline & 1 & 2 & 3 & 4 & 5 & 6 & 7 & 8 & 9 \\
\hline 1. EME & .86 & & & & & & & & \\
\hline 2. EBS & $.49 * *$ & .95 & & & & & & & \\
\hline 3. Attitude strength & $.59 * *$ & $.48^{* *}$ & N/A & & & & & & \\
\hline 4. Attitude correctness & $.59 * *$ & $.62 * *$ & $.63^{* *}$ & .92 & & & & & \\
\hline 5. Attitude clarity & $.45^{* *}$ & $.48^{* *}$ & $.57 * *$ & $.86^{* *}$ & .97 & & & & \\
\hline 6. Moral conviction & $.63^{* *}$ & $.41 * *$ & $.67 * *$ & $.51 * *$ & $.46^{* *}$ & .89 & & & \\
\hline 7. Social vigilantism & $.55^{* *}$ & $.46^{* *}$ & $.35 * *$ & $.39 * *$ & $.31 * *$ & $.45 * *$ & .89 & & \\
\hline 8. Self-righteousness & .10 & $.25 * *$ & -.04 & $.14^{*}$ & -.02 & .01 & $.31 * *$ & .46 & \\
\hline 9. Dogmatism & $.16^{*}$ & $.35 * *$ & $.14 *$ & $.28 * *$ & $.17 * *$ & $.15^{*}$ & $.34 * *$ & $.41 * *$ & .89 \\
\hline
\end{tabular}

Note. ${ }^{*} p<.05 .{ }^{*} p<.01$. The diagonal of the table lists the respective scale alphas. N/A $=$ the measure consistent of only one item. $\mathrm{EME}=$ environmental moral exporting. EBS = environmental belief superiority. 
Table 4

Regression models with environmental moral exporting, environmental belief superiority, and the interaction between the two measures predicting environmental conversational experiences, Study 2

\begin{tabular}{|c|c|c|c|c|c|c|c|c|c|c|c|c|}
\hline \multirow[b]{2}{*}{ Variable } & \multicolumn{3}{|c|}{$\begin{array}{c}\text { Two-Way } \\
\text { Conversations }\end{array}$} & \multicolumn{3}{|c|}{$\begin{array}{l}\text { Pessimism / } \\
\text { Frustration }\end{array}$} & \multicolumn{3}{|c|}{$\begin{array}{c}\text { Conversational } \\
\text { Confidence }\end{array}$} & \multicolumn{3}{|c|}{$\begin{array}{c}\text { Conversational } \\
\text { Enjoyment }\end{array}$} \\
\hline & $b$ & $S E$ & $d$ & $b$ & $S E$ & $d$ & $b$ & $S E$ & $d$ & $b$ & $S E$ & $d$ \\
\hline EME & $.36 * *$ & .07 & .60 & $.30 * *$ & .06 & .61 & -.01 & .07 & -.01 & $.72 * *$ & .08 & 1.06 \\
\hline EBS & $-.19 *$ & .08 & -.29 & $.24 * *$ & .06 & .46 & .14 & .07 & .22 & -.05 & .09 & -.06 \\
\hline EME x EBS & -.03 & .05 & -.06 & -.04 & .04 & -.10 & .05 & .05 & .14 & -.04 & .06 & -.08 \\
\hline$F(d f)$ & & $\begin{array}{c}8.73 \\
(3,282)\end{array}$ & & & $\begin{array}{c}27.32 \\
(3,282)\end{array}$ & & & $\begin{array}{c}1.92 \\
(3,282)\end{array}$ & & & $\begin{array}{c}34.44 \\
(3,282)\end{array}$ & \\
\hline Adjusted $R^{2}$ & & $.08 * *$ & & & $.22 * *$ & & & .01 & & & $.26 * *$ & \\
\hline
\end{tabular}

Note. ${ }^{*} p<.05 .{ }^{*} p<.01$. EME = environmental moral exporting. EBS = environmental belief superiority. 
Table 5

Regression models with environmental moral exporting, environmental belief superiority, and the interaction between the two measures predicting past efforts to influence others, perceptions of confrontation efforts, and willingness to confront transgressors, Study 2

\begin{tabular}{|c|c|c|c|c|c|c|c|c|c|}
\hline \multirow[b]{2}{*}{ Variable } & \multicolumn{3}{|c|}{$\begin{array}{c}\text { Past } \\
\text { Efforts }\end{array}$} & \multicolumn{3}{|c|}{$\begin{array}{c}\text { Perceived } \\
\text { Effectiveness } \\
\end{array}$} & \multicolumn{3}{|c|}{$\begin{array}{c}\text { Willingness to } \\
\text { Confront }\end{array}$} \\
\hline & $b$ & $S E$ & $d$ & $b$ & $S E$ & $d$ & $b$ & $S E$ & $d$ \\
\hline EME & $.58 * *$ & .07 & .95 & $.29 * *$ & .03 & 1.04 & $.65 * *$ & .06 & 1.37 \\
\hline EBS & $.19 *$ & .08 & .31 & -.01 & .04 & -.04 & -.06 & .06 & -.11 \\
\hline EME x EBS & .07 & .05 & .18 & .02 & .02 & .12 & $.08 *$ & .04 & .26 \\
\hline$F(d f)$ & & $\begin{array}{c}40.79 \\
(3,280)\end{array}$ & & & $\begin{array}{c}33.16 \\
(3,281)\end{array}$ & & & $\begin{array}{c}57.58 \\
(3,282)\end{array}$ & \\
\hline Adjusted $R^{2}$ & & $.30 * *$ & & & $.25 * *$ & & & $.37 * *$ & \\
\hline
\end{tabular}

Note. ${ }^{*} p<.05 .{ }^{* *} p<.01 . \mathrm{EME}=$ environmental moral exporting. EBS = environmental belief superiority. 
Figure 1

Confirmatory factor analysis model (Model 3) with seven items, Study 1

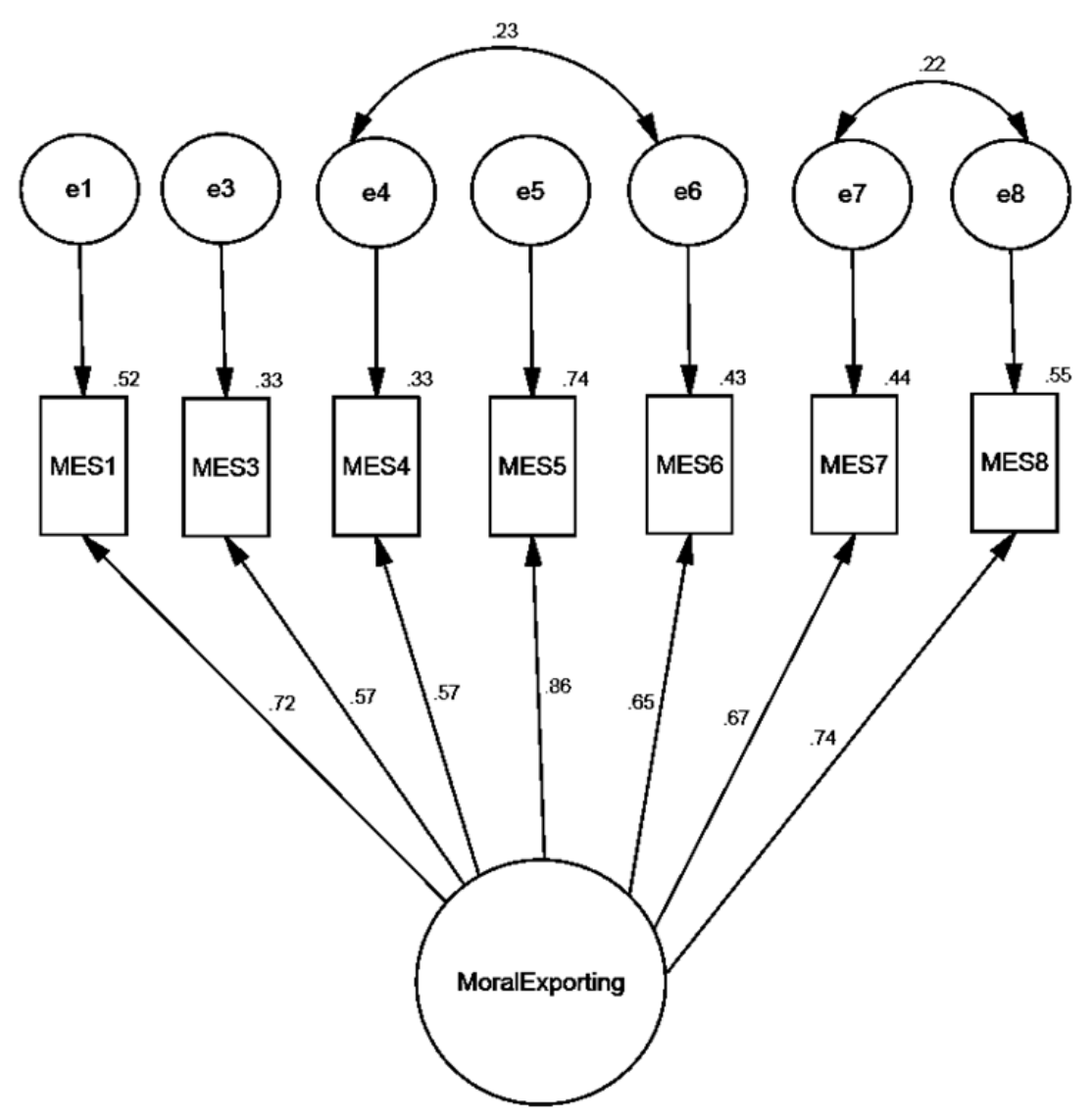


Acknowledgements

This work was supported in part by the National Science Foundation through a Graduate Research Fellowship to Alexander Maki. 